\title{
Relation between Inclusion Surface and Acicular Ferrite in Low Carbon Low Alloy Steel Weld
}

\author{
Tomonori YAMADA, ${ }^{1)}$ Hidenori TERASAKI ${ }^{2)}$ and Yu-ichi KOMIZO ${ }^{21}$ \\ 1) Graduate School of Engineering, Osaka University, 11-1 Mihogaoka, Ibaraki, Osaka 567-0047 Japan. \\ 2) Joining and Welding Research Institute, Osaka University, 11-1 Mihogaoka, Ibaraki, Osaka 567-0047 Japan.
}

(Received on November 14, 2008; accepted on February 18, 2009)

\begin{abstract}
The inclusion of low carbon submerged arc weld metals of a Ti-B system with different aluminum contents has been studied. The inclusions contributing to acicular ferrite nucleation were multi-phase consisting of $\mathrm{MnS}, \mathrm{MnAl}_{2} \mathrm{O}_{4}$ and amorphous phases. In the energy dispersive X-ray spectroscopy mapping analysis, inclusions were surrounded by a titanium-rich layer. This layer was analysed as Ti-O by energy disperse X-ray spectroscopy spectrum from the interface between inclusion and ferrite. The selected area diffraction pattern of inclusion surface was characterized as TiO. The acicular ferrite had Baker-Nutting orientation relationship with this $\mathrm{TiO}$ layer on the inclusions surface, and the lattice misfit was $3.0 \%$. Therefore, it was supposed that the narrow $\mathrm{TiO}$ on the inclusion surface promotes acicular ferrite nucleation supplying low interface energy.
\end{abstract}

KEY WORDS: weld metal; acicular ferrite; inclusion; TiO; nucleation.

\section{Introduction}

In low carbon low alloy steel welds, acicular ferrite is regarded as the most desirable microstructural feature, in view of strength and toughness. It is known that the inclusions in weld metal strongly contribute to the nucleation of acicular ferrite. Especially, titanium oxide, titanium nitride and galaxite have often been noted as effective nucleants of acicular ferrite. ${ }^{1-3)}$ Generally, these inclusions were evaluated by the lattice matching theory ${ }^{4)}$ to the role of inclusions in heterogeneous nucleation. In this case, lattice misfits of $\mathrm{TiO}$, TiN and $\mathrm{MnAl}_{2} \mathrm{O}_{4}$ were $3.0 \%, 4.6 \%$ and $1.8 \%$, respectively. ${ }^{1)}$ Moreover, MnS inclusions has been suggested that those absorb austenite stabilizing element of manganese from the steel phase and give the preferential ferrite formation from austenite due to raising its transition temperature. ${ }^{5-7)}$

In the previous study, ${ }^{8,9)}$ the inclusions contributing to acicular ferrite formation were investigated to clarify its mechanism in several weld metals with different $\mathrm{Al} / \mathrm{O}$ ratio. In $\mathrm{Al} / \mathrm{O}$ ratios of 0.48 and 0.73 at which acicular ferrite was observed, inclusions were consisted of amorphous phase of a $\mathrm{Si}-\mathrm{Mn}$ system, $\mathrm{MnS}$ and $\mathrm{MnAl}_{2} \mathrm{O}_{4}$. The lattice misfits of these inclusions were considerably high, and it was not a considerably effective site. However, these inclusions were surrounded by titanium enriched layer by EDS mapping analysis. Therefore, it thought that this titanium enriched layer on inclusion surface was related to acicular ferrite formation.

In the present work, this layer on inclusion surface of sample with different $\mathrm{Al} / \mathrm{O}$ ratio was investigated from the crystallographic points of view and the lattice misfit between the layer and acicular ferrite was investigated.

\section{Experimental Procedure}

The tested material is low carbon Ti-B submerged arc weld metals with an oxygen content of about $450 \mathrm{ppm}$. The welding speed and heat input were $0.0217 \mathrm{~m} \mathrm{~s}^{-1}$ and $5.16 \times 10^{6} \mathrm{~J} \mathrm{~m}^{-1}$. Table 1 shows the chemical compositions of weld metals used. The compositions of inclusions were varied by changing aluminum content while the contents of the other elements kept constant. The $\mathrm{Al} / \mathrm{O}$ ratios (mass ratio) were $0.48,0.73$ and 1.52 . It was confirmed that the microstructure of $\mathrm{Y} 1(\mathrm{Al} / \mathrm{O}=0.48)$ and $\mathrm{Y} 2(\mathrm{Al} / \mathrm{O}=0.73)$ consists mainly of acicular ferrite nucleated from inclusions in high temperature intragranular austenitic phases and that the microstructure of $\mathrm{Y} 3(\mathrm{Al} / \mathrm{O}=1.52)$ consists mostly of bainite with ferrite laths formed from austenite grain boundaries during cooling. ${ }^{9)}$

Table 1. Chemical compositions of weld metals used (mass \%).

\begin{tabular}{|c|c|c|c|c|c|c|c|c|}
\hline & $\mathrm{C}$ & $\mathrm{Si}$ & $\mathrm{Mn}$ & $\mathrm{Al}$ & $\mathrm{Ti}$ & $\mathrm{B}$ & $\mathrm{O}$ & $\mathrm{N}$ \\
\hline $\mathrm{Y} 1$ & 0.090 & 0.35 & 1.72 & 0.022 & 0.014 & 0.0035 & 0.046 & 0.0042 \\
\hline $\mathrm{Y} 2$ & 0.085 & 0.37 & 1.75 & 0.035 & 0.015 & 0.0040 & 0.048 & 0.0041 \\
\hline $\mathrm{Y} 3$ & 0.086 & 0.39 & 1.81 & 0.073 & 0.013 & 0.0040 & 0.048 & 0.0035 \\
\hline
\end{tabular}




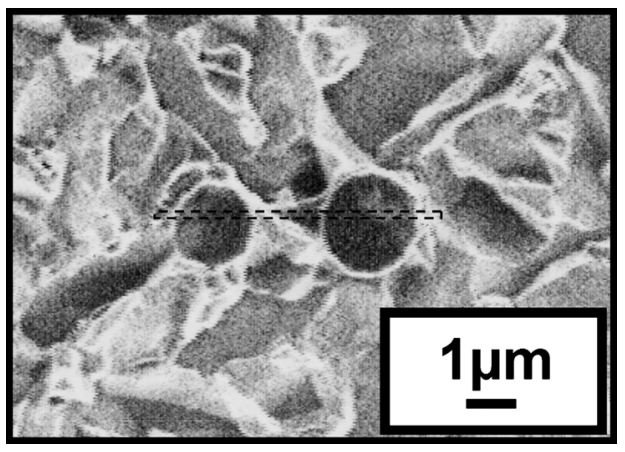

Fig. 1. Scanning ion microscopy (SIM) image of acicular ferrite in $\mathrm{Al} / \mathrm{O}$ ratio of 0.73 .

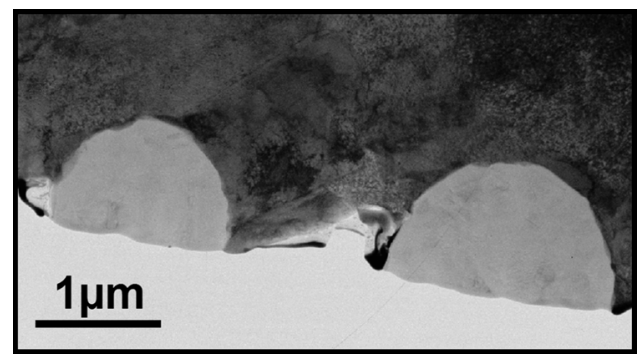

Fig. 2. Bright field image of the travel section of same region as Fig. 1.

In the present work, especially, inclusions surface were investigated. Figure 1 shows the scanning ion microscopy (SIM) image of inclusions in acicular ferrite structure of Y2. It though that these inclusions are contributed to acicular ferrite formation. Then, the authors made thin foils which including inclusions and ferrite by focused ion beam (FIB) device. The accelerated voltage of $200 \mathrm{kV}$ was used to observe the thin foils in transmission electron microscope (TEM). Figure 2 shows the bright field image of inclusions of Fig. 1 by TEM. The element analyses of inclusions made by energy disperse X-ray spectroscopy (EDS).

\section{Results and Discussion}

The author has made many thin foils and has been observed inclusions to clarify formation mechanism of acicular ferrite. ${ }^{8}$ Figure 3(a) shows bright field image from reheated sample of Y1. This inclusion mainly consisted of amorphous phase and partly consisted of MnS. It thought that amorphous phase and acicular ferrite are adjacent from bright field image. In this case, no discussion arises concerning about a lattice misfit between the nucleated ferrite and inclusion. However, these inclusions were surrounded by titanium-enriched layer, as show in Fig. 3(b). That is, the narrow titanium-enriched layer touches acicular ferrite. Figure 3(c) shows EDS spectrum from the interface between inclusion and acicular ferrite. There is $\mathrm{Cu}$ peaks because of $\mathrm{Cu}$ mesh. The Fe peak is from the matrix. The $\mathrm{Si}$ and $\mathrm{Mn}$ peaks are from the inclusion. It is thought that the $\mathrm{C}$ peak is contamination. Therefore, the $\mathrm{O}$ and $\mathrm{Ti}$ peaks are from inclusion surface. That is, the narrow titanium-enriched layer is Ti-O system. Figure 3(d) shows the selected area diffraction pattern from the interface between inclusion and ferrite (location A). This crystal structure resulted in $\mathrm{TiO}$ and fer-

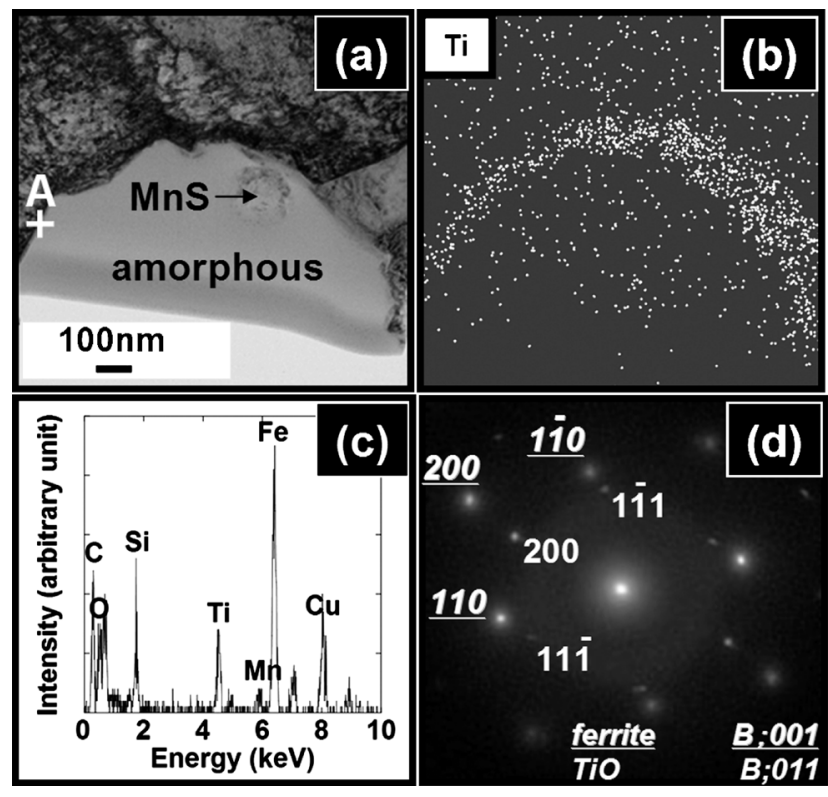

Fig. 3. TEM analysis of inclusion in $\mathrm{Y} 1(\mathrm{Al} / \mathrm{O}=0.48$, re-heated). (a) Bright field image. (b) EDS mapping analysis. (c) EDS spectrum (location A). (d) Selected area diffraction pattern (location A).
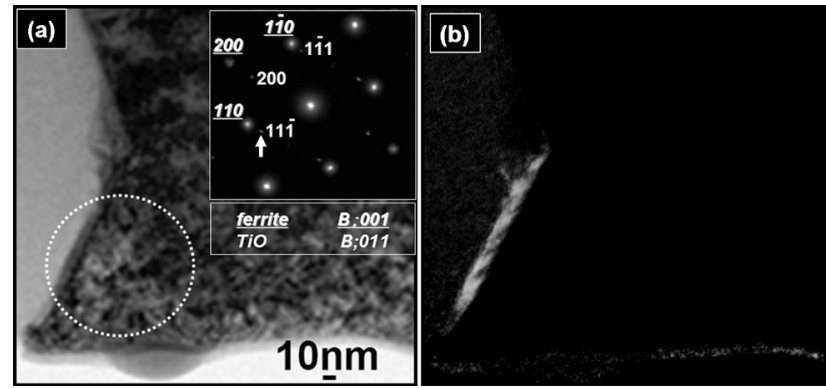

Fig. 4. TEM analysis of inclusion surface in $\mathrm{Y} 1(\mathrm{Al} / \mathrm{O}=0.48$, asweld). (a) Bright field image and selected area diffraction pattern of interface. (b) Dark field image of same region as (a).

rite. Figure 4(a) shows the bright field image and selected area diffraction pattern on inclusion surface of as-weld sample of Y1. In this case, the crystal structure resulted in $\mathrm{TiO}$ and ferrite. The TiO thickness was about $10 \mathrm{~nm}$ from dark field image which taken using spot of the (111) diffraction of TiO, as show in Fig. 4(b).

$$
\begin{gathered}
\operatorname{TiO}\{100\} / / \alpha-\operatorname{Fe}\{100\} \\
\operatorname{TiO}\langle 011\rangle / / \alpha-\operatorname{Fe}\{001\}
\end{gathered}
$$

The relations were found, as shown in Fig. 3(d) and Fig. 4(b). This result shows that they have Baker-Nutting (B-N) orientation relationship. ${ }^{10,11)}$

On the other hand, Fig. 5 shows the inclusions of Y2 ((a) and (b) is re-heated, (c) and (d) is as-weld). These inclusions consist of mainly $\mathrm{MnAl}_{2} \mathrm{O}_{4}$ and also partly amorphous phase and/or $\mathrm{MnS}$. In this case, the $\mathrm{MnAl}_{2} \mathrm{O}_{4}$ and acicular ferrite adjacent from bright field image. The ideal lattice misfit was $1.8 \%$ between $\mathrm{MnAl}_{2} \mathrm{O}_{4}$ and acicular ferrite. However, the lattice misfit was $8.6 \%{ }^{12)}$ in an actual interface. It was not able to be considered as an effective nu- 


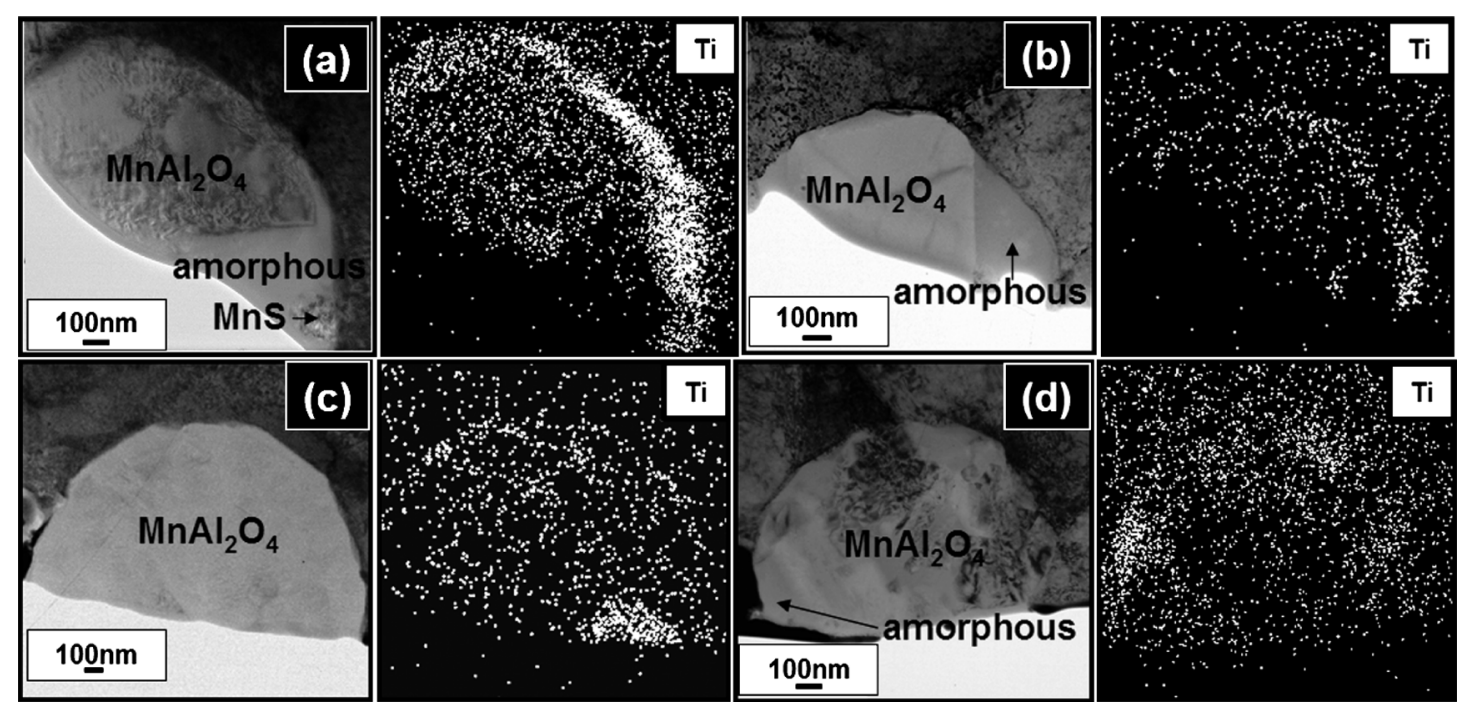

Fig. 5. Bright field images and EDS mapping analyses. (a) and (b) is re-heated. (c) and (d) is as-weld.

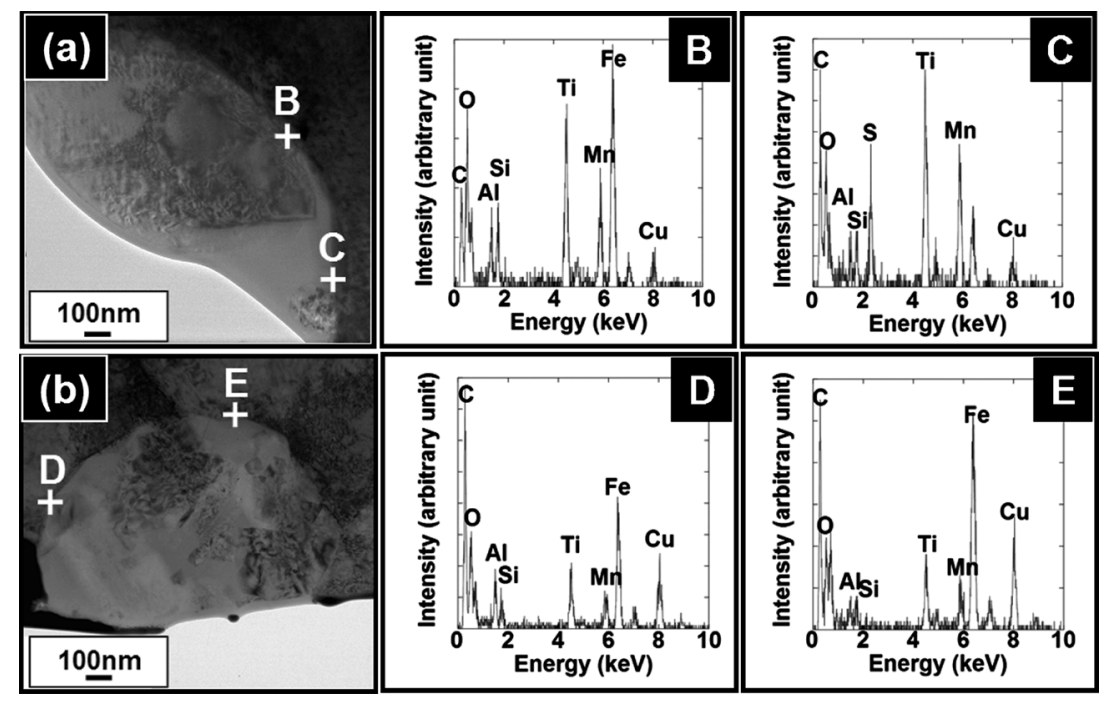

Fig. 6. Bright field images and EDS spectrum of each location. (a) is re-heated and (b) is as-weld.

cleation site. In the EDS mapping analysis of titanium, these inclusions were surrounded by titanium-enriched layer, same as inclusion in Y1. Therefore, because of the titanium-enriched layer on inclusion surface, the lattice misfit between $\mathrm{MnAl}_{2} \mathrm{O}_{4}$ and acicular ferrite was considerably high. Figure 6 shows EDS spectrum ((a) is re-heated and (b) is as-weld). Also in this case, there is $\mathrm{Cu}$ peak because of $\mathrm{Cu}$ mesh and $\mathrm{C}$ peak due to contamination. The $\mathrm{O}$ and $\mathrm{Ti}$ peaks were detected from inclusion surface, same as inclusion in Y1. Figure 7 shows the bright field image of inclusion in $\mathrm{Y} 2$, the corresponding selected area diffraction pattern from inclusion surface and dark field image which was taken using spot of the (111) diffraction of $\mathrm{TiO}((\mathrm{a})$ is reheated and (b) is as-weld). The TiO size was about 20-40 nm from dark field images.

$$
\begin{gathered}
\operatorname{TiO}\{100\} / / \alpha-\mathrm{Fe}\{100\} \\
\operatorname{TiO}\langle 011\rangle / / \alpha-\mathrm{Fe}\langle 001\rangle
\end{gathered}
$$

The relations were found in selected area diffraction pattern of Fig. 7. This result same as Y1. Therefore, the nano-scale $\mathrm{TiO}$ layer on inclusion surface has B-N orientation relation ship with acicular ferrite, same as Y1. The lattice misfit was $3.0 \%$ and this result shows that between $\mathrm{TiO}$ and acicular ferrite satisfies lattice matching theory.

On the other hand, Fig. 8 shows the inclusion in Y3 in which only bainite was formed. This inclusion was single phase $\mathrm{Al}_{2} \mathrm{O}_{3}$ and no titanium enriched layer existed. ${ }^{12)}$

Therefore, it can be considered that the nano-scale TiO layer on the inclusion surface of Y1 (both re-heated and as weld) and Y2 (both re-heated and as weld) promotes acicular ferrite nucleation supplying low interface energy.

\section{Conclusions}

The inclusions in low carbon Ti-B weld metals with three levels of $\mathrm{Al} / \mathrm{O}$ ratio were analyzed to clarify the mechanism of acicular ferrite formation. The findings obtained in the present research are as follows.

(1) In the sample with $\mathrm{Al} / \mathrm{O}$ ratio of 0.48 and 0.73 , the inclusions of neighboring with acicular ferrite formation were surrounded by narrow $\mathrm{TiO}$ layers of which the thickness range was $10-40 \mathrm{~nm}$.

(2) The TiO layer has Baker-Nutting orientation rela- 


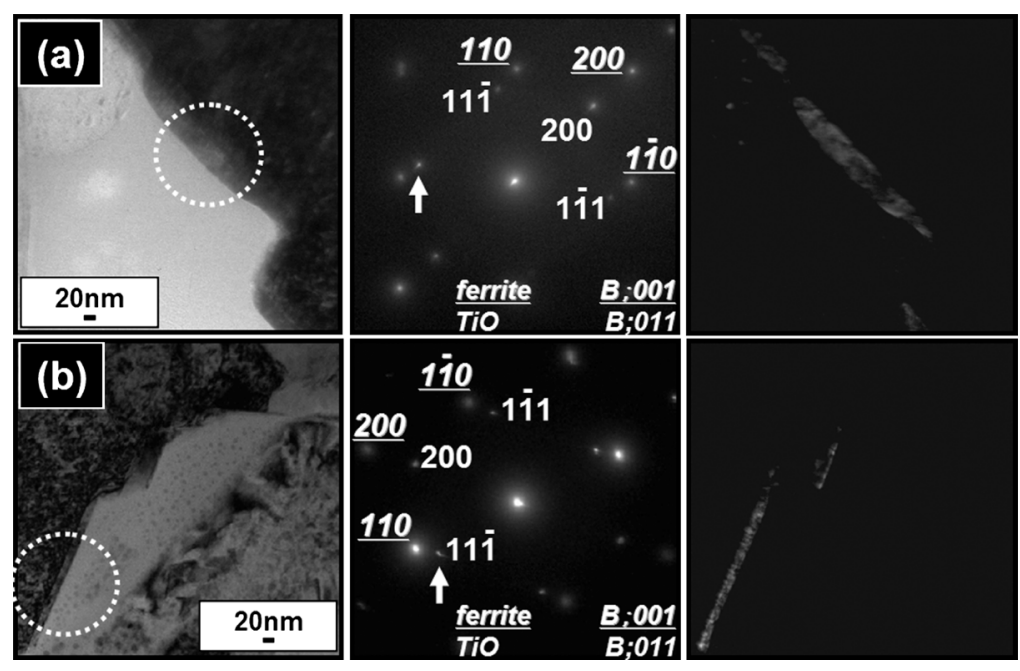

Fig. 7. TEM analyses of inclusion surface. (a) is re-heated and (b) is as-weld.

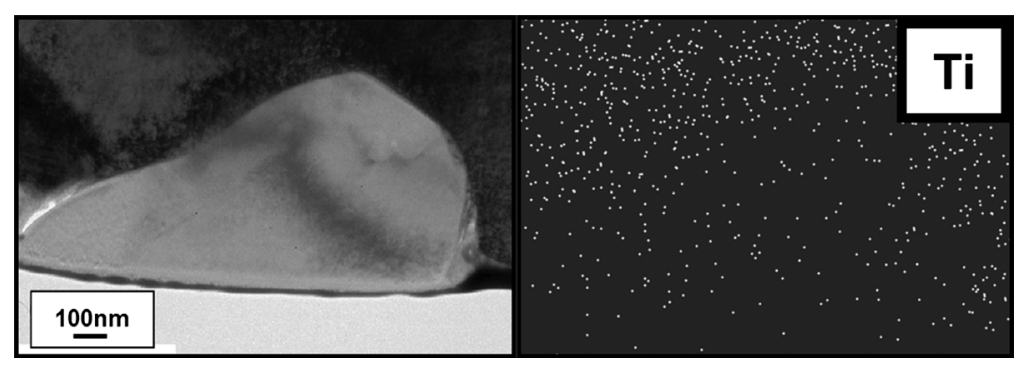

Fig. 8. TEM analysis of inclusion in Y3 (re-heated).

tionship with acicular ferrite and the lattice misfit was 3.0\% between them.

(3) It was supposed that the $\mathrm{TiO}$ on the inclusion surface contributes to the heterogeneous nucleation of acicular ferrite supplying low interface energy.

\section{Acknowledgements}

The authors are grateful to Mr. E. Taguchi, Research Center for Ultra-High Voltage Electron Microscopy, Osaka University, Osaka, Japan, for his help in EDS mapping.

\section{REFERENCES}

1) A. R. Mills, G. Thewlis and J. A. Whiteman: Mater. Sci. Technol., 3 (1987), 1051

2) G. Thewlis: Mater. Sci. Technol., 10 (1994), 110.

3) O. Grong, A. O. Kluken, H. K. Hylund, A. L. Dons and H. Hjelen:
Metall. Mater. Trans. A, 26A (1995), 525.

4) B. L. Bramfitt: Metall. Trans., 1 (1970), 1987.

5) J. M. Greeg and H. K. D. H. Bhadeshia: Acta Metal. Mater., 42 (1994), 3321.

6) S. Aihara, G. Shigesato, M. Sugiyama and R. Uemori: Nippon Steel Tech. Rep., 381 (2004), 39.

7) Y. Oya, T. Yoshikawa and K. Morita: Tetsu-to-Hagané, 93 (2007), 769.

8) T. Yamada, H. Terasaki and Y. Komizo: Q. J. Jpn. Weld. Soc., 25 (2007), 416.

9) T. Yamada, H. Terasaki and Y. Komizo: Q. J. Jpn. Weld. Soc., 25 (2007), 514

10) S. Zhang, N. Hattori, M. Enomoto and T. Tarui: ISIJ Int., 36 (1996), 1301.

11) M. Mizuno, I. Tanaka and H. Adachi: Acta Mater., 46 (1998), 1637.

12) T. Yamada, H. Terasaki and Y. Komizo: Sci. Technol. Weld. Joining, 13 (2008), 118 